\title{
Analysis of the road network structures based on street connectivity.
}

\author{
Análisis de las estructuras de la red de vialidades basado en la conectividad de \\ las calles.
}

Recibido: enero 2020

Aceptado: marzo 2020

\section{Abstract}

The following article proposes a method to identify structures inside a road network with a flow-base community detection algorithm implemented on a graph representing the city road network.

According to the results obtained in the cities of Mexico and Monterrey, the method effectively divides road infrastructure into several communities and preserves geographical neighboring. The frontiers of communities match administrative divisions along with other frontiers inside the city.

The identification of communities could beuseful to study the heterogeneity of street connectivity inside the city which could lead to improvements in urban mobility or even the application of public policies.

\section{Keywords:}

road networks; connectivity of communities; space syntax

\author{
María Erandi Flores Romero ${ }^{1}$ \\ Irving Omar Morales Agiss ${ }^{2}$ \\ Liliana Beatríz Sosa Compeán ${ }^{3}$
}

\section{Resumen}

El siguiente artículo propone un método para identificar estructuras dentro de una red de vialidades con un algoritmo de detección de comunidad basado en flujos, implementado en un grafo que representa la red de vialidades de la ciudad.

De acuerdo con los resultados obtenidos en las ciudades de México y Monterrey, el método divide efectivamente la infraestructura vial en varias comunidades y preserva la vecindad geográfica. Las fronteras de las comunidades coinciden con las divisiones administrativas junto con otras fronteras dentro de la ciudad.

La identificación de comunidades podría ser útil para estudiar la heterogeneidad de la conectividad de las calles dentro de la ciudad, lo que podría conducir a mejoras en la movilidad urbana o incluso a la aplicación de políticas públicas.

\section{Palabras Clave:}

redes de vialidades; conectividad de comunidades; sintaxis espacial

\footnotetext{
${ }^{1}$ Nacionalidad: Mexicana; adscripción: Universidad Nacional Autónoma de México, Investigadora becaria del CONACYT; E mail: maria.erandi@ ciencias.unam.mx

2 Nacionalidad: mexicano; adscripción: jefe del departamento de análisis de datos en Digital State; Doctor en física por parte del Instituto de Ciencias Nucleares de la UNAM; Miembro del Sistema Nacional de Investigadores nivel I; E mail: irvingfisica@gmail.com

${ }^{3}$ Nacionalidad: Mexicana; adscripción: profesor-investigador de la Facultad de Arquitectura de la Universidad Autónoma de Nuevo León (UANL); Doctora en filosofía con orientación en arquitectura y asuntos urbanos, por la Universidad Autónoma de Nuevo León (UANL); miembro del Sistema Nacional de Investigadores desde el 2014; E mail: lilisosa@hotmail.com
} 


\section{INTRODUCTION.}

Since the 20th century, cities are increasing in size and population all over the globe. From then on, nearly half of the world population have swapped rural locations to urban areas (Ritchie \& Roser, 2018). Particularly in Mexico, urban population have increased by $35 \%$ over the last five decades (INEGI, 2010), and currently $72 \%$ of the population in Mexico lives among its cities (SEDESOL \& CONAPO, 2012). Dynamics involved in cities are relevant not only for the global trend towards urbanization, but because urban areas are major structures in our society. They facilitate the distribution of goods and commodities for a large amount of people in a reduced area and by gathering human capital they create wider markets, foster job specialization, increase social interactions (Schläpfer et al, 2014), develop knowledge and promote inventions and innovations (Bettencourt et al, 2007). Cities are complex and self-organizing systems (White, Engelen \& Uljee, 2015), that can be described as a collective result of interactions between two elements: a spatial structure consisting of network linked centers conforming the physical aspects of the city (buildings, roads, houses) and the human activity generating movement through social and economic occupations (Hillier, 2009). It is this movement together with the spatial structure what creates, modifies and maintain urban areas (Hillier, 1996)

For instance, this regulatory process can be seen in the construction of roads, that is strongly influenced -among other aspects- by land use patterns, meanwhile the human activity that define those land use patterns is governed by the actual physical structure of the city.

Previous work have analyzed the structure created by city dynamics focusing on the social movement, for instance, (Roth et al, 2011) analyzed the trips inside the metro of London to find the city activity centers, (Ratti et al, 2010) used a modularity optimization method to find a partition of Great Britain according to the telephone call network, (Rinzivillo et al, 2012) analyzed mobility behavior with the trajectories and endpoints of GPS tracked vehicles to find clusters, that were then compared with administrative regions and (Zhong et al, 2014) used the fare card information of public transport in Singapore to find regions in the city reflecting the mobility of Singapore inhabitants.

In this analysis we focus on the less studied approach of city dynamics created by the road network infrastructure, because movement inside the city is related with the topological and geometric complexity of the road network (Hillier \& Iida, 2005). Street interconnection determines accessibility, and consequently, imposes restrictions in the way inhabitants move around, how they perceive their city and consequently to what extent they can modify it (White, Engelen \& Uljee, 2015) (Sosa, 2017). Therefore, if the road network is a core urban element influencing long term dynamics, its structure should portray features of the city.

Graphs $^{4}$ are a helpful tool to show inner structures and help to identify clusters of elements, as they portray a simplified version of the system that only focus on interactions among their elements. The range of areas in which graph analysis is used vary from detecting criminal organizations (Ferrara et al, 2014) to describe brain structures (Reijneveld et al, 2007) or infer economic status from social network location (Luo, 2016).

Aspects of the city can be characterized by the broad variety of functions offered by graph analysis, for instance, (Rinzivillo et al, 2012) and (Zhong et al, 2014) used graph representations of their systems in order to find clusters of routes inside the city. In this analysis, a graph is constructed with streets represented as vertexes depicted as edges, meaning that this depiction preserves street continuity, as paths inside the graph represent actual routes.

The approach to analyze the division created by the connectivity of the streets in the city was to use the Infomap algorithm ${ }^{5}$ that detects communities indirectly by minimizing the description of flow (modeled by a random walk) driven through the edges of a graph. Communities were compared with delegations and neighborhoods that had similar areas and match geographically, additionally, the distribution of betweenness centrality was compared among communities, since it's expected for the graph partition ${ }^{6}$ to reflect how well connected are the streets.

\footnotetext{
${ }^{4}$ A graph $\mathrm{G}$ is a mathematical object defined by an order pair of the set of vertexes or nodes $\mathrm{V}(\mathrm{G})$ the elements of the system- and the set of edges or links $E(G)$-indicating relations between the elements by subsets of two (not necessarily distinct) vertexes-.

${ }^{5}$ Appendix below provides a detailed description of its operation.

${ }^{6} \mathrm{As}$ in the mathematical sense a division of a set into disjoint subsets.
} 
Since, the cities are a heterogeneous system, the identification of communities could help urban mobility by proposing new routes for public transportation, finding area where bridges and streets are needed or minimizing routes for the distribution of resources. It could also help to determine the optimal location for hospitals or schools based on its accessibility and area coverage, help to decrease disparities among the city by identifying the areas that should be prioritize in the urbanization plans or even contribute to predict how a city will evolve.

\section{MATERIALS AND METHODS.}

\section{Analysis of the road network.}

The road network analysis consists of three phases: construction of the graph with the information of the road network, search of substructures in the graph by minimizing the description length of flow inside the graph and finally, interpretation of the communities back in the original road network.

\section{Construction of the graph.}

A graph $G$ is defined by an order pair of the set of vertexes (or nodes) $V(G)$ and the set of edges (or links) $E(G)$, therefore, a graph depends solely on how those sets are defined. Thought it seems natural to use street segments as the links and the ends of those segments as nodes to create the graph associated with the road network (representation usually named simple graph), that depictions are close to regular grids, making difficult to search for hubs, also it divides a single street into several segments, hampering the analysis of road dynamics and lastly the inconsistencies, since a node can represent an intersection, the end of a road or even a sharp turn. (Marshall, 2016).

In order to overcome those problems, the graph representation used for the analysis focuses on the streets while preserving the continuity of streets as in the original network (named dual graph in the literature). Each vertex was paired with the set of coordinates describing a street and vertexes where joined by an edge only if there were point coincidences in their list of coordinates: when streets had an ordered pair of coordinates in common, it was assumed that they do intersect each other. Formally, the graph consisted of all streets in the city represented with vertexes $V(G)$ and their intersections as links. Due to the lack of street direction information in our data, edges were bidirectional, meaning that all streets could be reach by any of their intersections, however, if the information is given, it is recommended to create an oriented graph, to ensure that the flow inside the graph models realistically city dynamics.

To test the method, we used the vector data of Monterrey and Mexico City road networks. Such data was created in 2010 by the National Institute of Statistics and Geography in Mexico (INEGI) and was consulted on October of 2018.

Figure 1. Comparison between simple and dual graphs

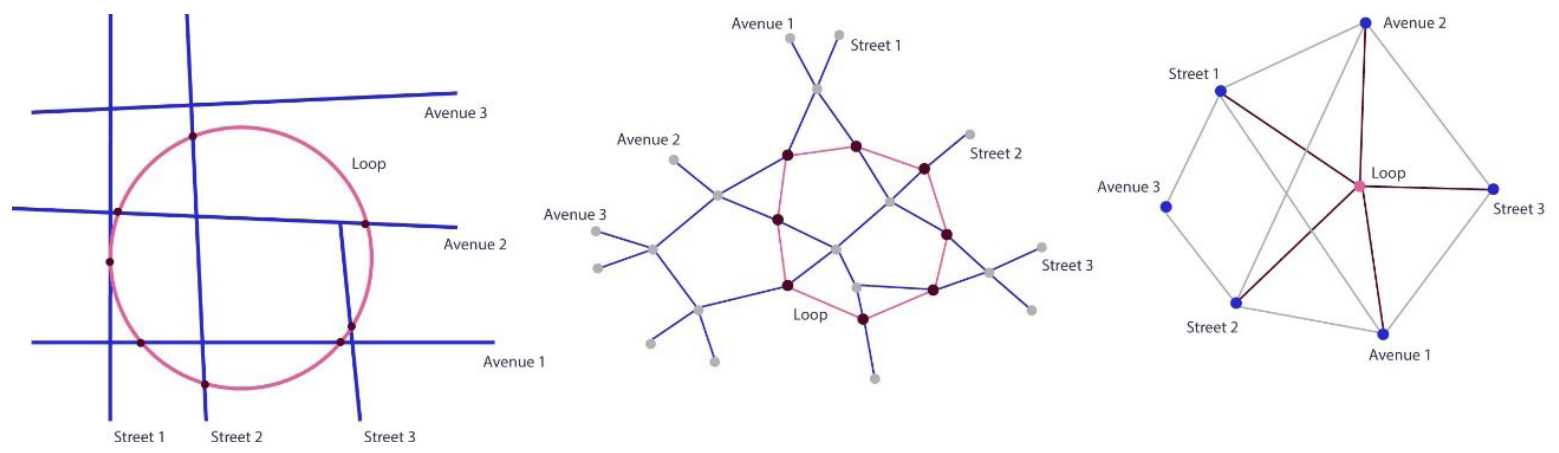

A: the original road network, B: its simple graph, C: its dual graph. Although both graphs keep network properties like street connectivity, identifying a street and its intersections in the dual representation is easier and faster compared with the simple graph. In order to compare depictions the intersections were drawn in gray, street segments in blue and the streets segments forming a loop with their intersections were highlighted in pink and dark red respectively.

\footnotetext{
${ }^{7}$ According to the mathematical definition, this graph is NOT the dual of the road network.
} 


\section{Search of substructures.}

The algorithm Infomap finds the best partition by creating modules in a random form, therefore, it is recommended to repeat the process several times. In this analysis the number of trials (repetitions before picking the best solution) was set to 20 . Additionally, street membership was restricted to only one community per level with the option no overlapping module. Additional information of the options provided by Infomap can be found in www.mapequation.org/code.html.

Communities obtained by the algorithm are grouped into different levels that follow a hierarchy: first level communities gather the communities of the second level and soon, meaning that the average area covered by a community gets bigger as the level decreases, and contrary: deeper in hierarchy means smaller groups of streets and consequently less area covered. For example, the road network of Monterrey city generates communities at 6 levels of depth; the first one with only 5 communities, each gathering 2776 streets approximately, the second composed of 48 communities, each with around 114 streets and so on until the last level, composed of 1749 communities, each grouping on average 7 streets.

Figure 2. An example of the interpretation of communities

A: the first level communities found in the Monterrey's road network graph and B: the interpretation of those communities in Monterrey street system.

\section{Interpretation of communities.}

Communities described in the output file are interpreted back in the original road network by identifying each vertex with the street coordinates it represent, once is done, each vertex can be grouped into their respective communities to generate a map showing how the partition of the graph looks in the real network at each level.

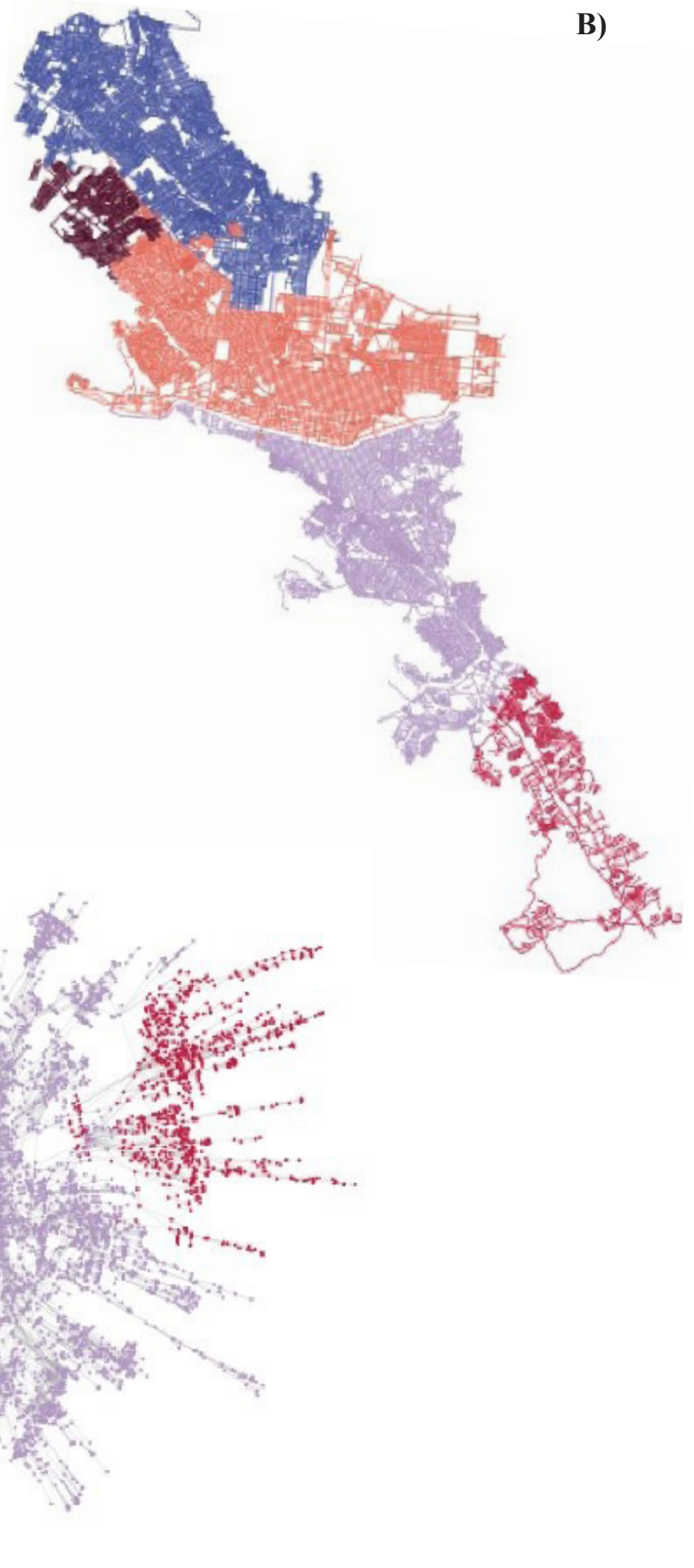




\section{COMPARISON WITH}

\section{ADMINISTRATIVE REGIONS.}

In order to compare the administrative regions to sets of lines describing street communities, its necessary to assign an area for those communities. The approach was to transform each line (street) in a polygon by creating a shifted duplicate of the line and join it with the original to construct a georeferenced polygon with the line shape. Community size varies widely even at the same level, therefore, communities from all levels were selected based on whether the area in which the streets were bounded was similar to the average area for those administrative regions, and finally for each administrative entity, the community with the smallest difference between their mean coordinates was selected (it a community meet all restrictions). Finally, the comparison was done by counting the pixel coverage of an image in which of the street polygons of a community and the administrative region are overlapped.

Figure. 3 An example of the process to compare communities and administrative entities

A: Selection of communities with similar areas to the administrative regions, B: Selection of the closest community for a specific entity, C: creation of the street polygons and D: image created next to its pixel count.

A)

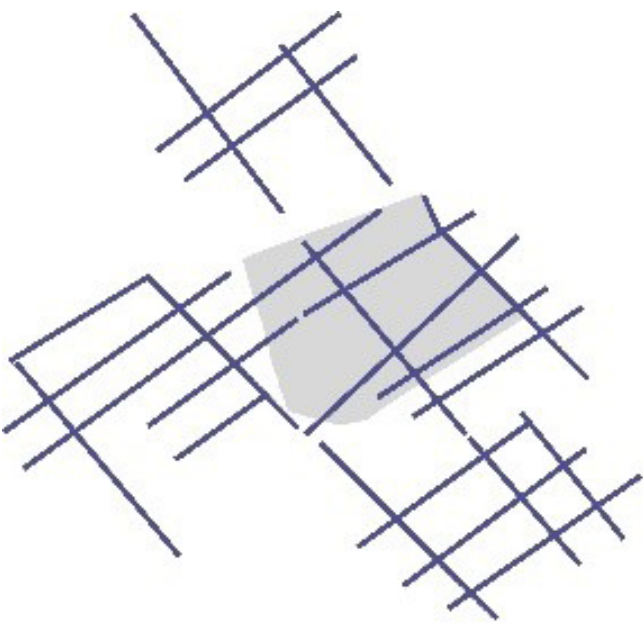

B)

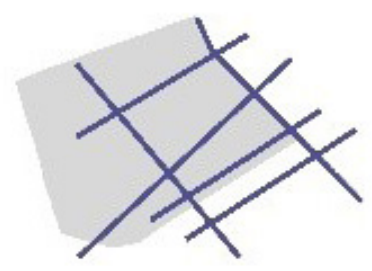

C)

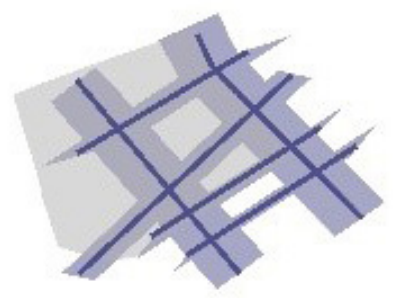

D)

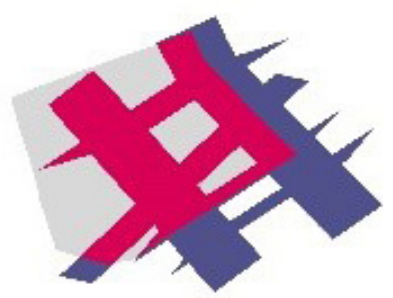




\section{RESULTS.}

The cities selected to analyze its road network structure were Monterrey and Mexico City, both important cities in Mexico, but with different areas, population and dynamics. In the fig. 4 we present the distribution of community size at different levels for Monterrey and Mexico City, additionally, maps portraying the road network partitions for each city at different levels are featured below. Communities are colored based on the number of streets they gather: red tones indicate fewer streets meanwhile blue tones represent communities that gather several streets. (in relation to the other communities of that same level)

Figure 4. Distribution of community size at different levels

A: Monterrey levels, B: Mexico City levels.

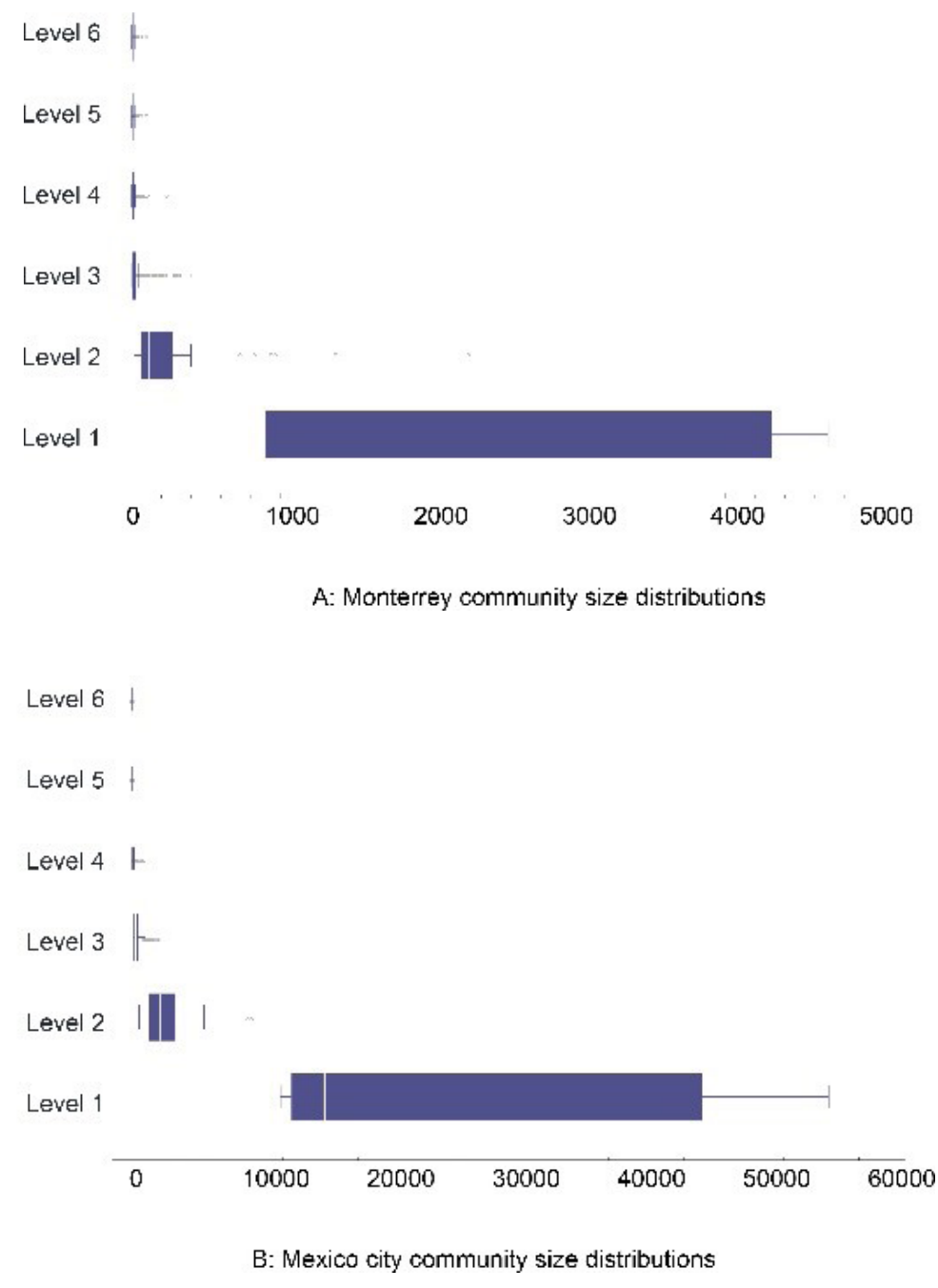


Figure 5. Partition levels of Monterrey road network structure
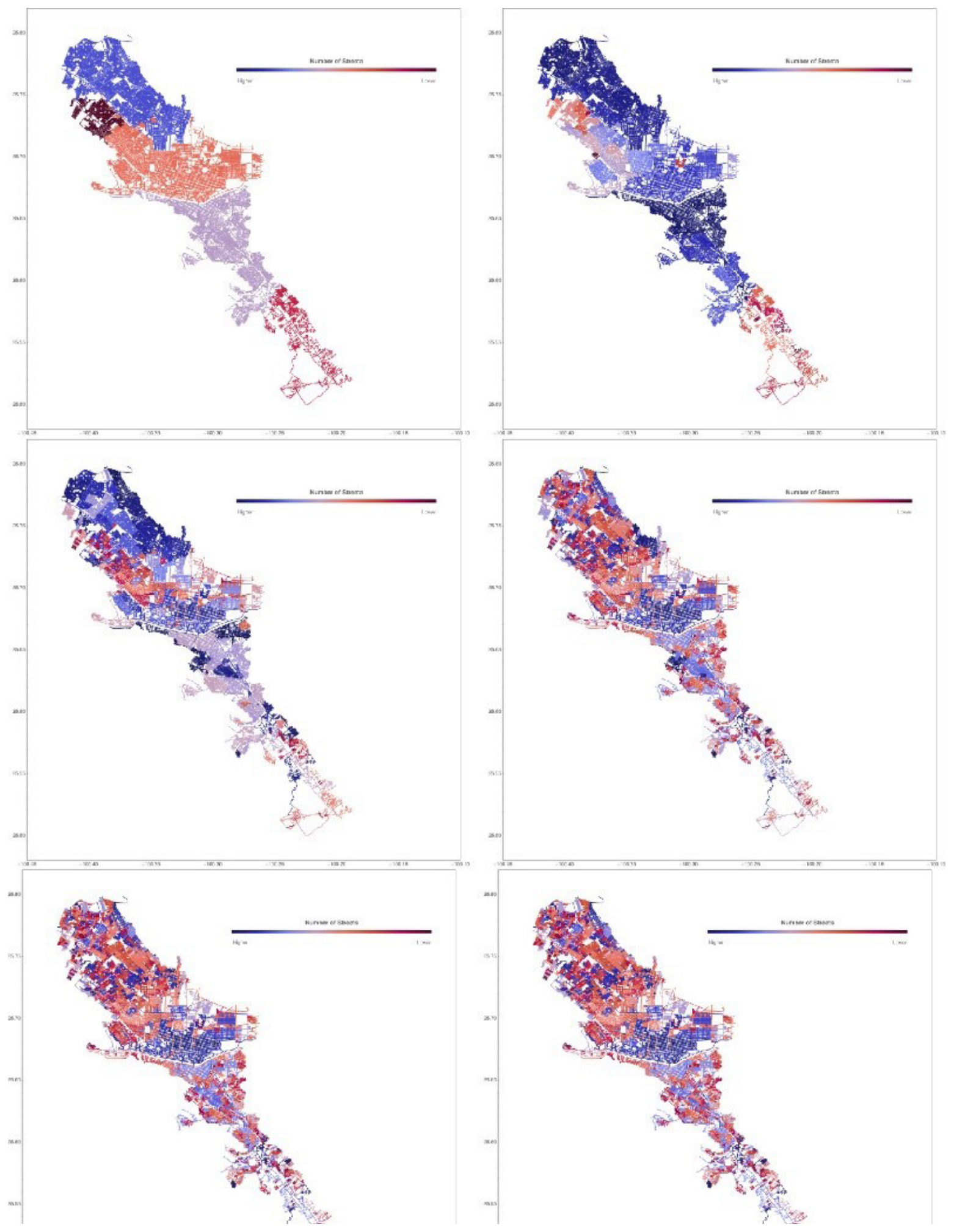

A: First Level, B: second level, C: third level, D: fourth level, E: fifth level, F: sixth level. 
Figure 6. Partition levels of Mexico City road network structure

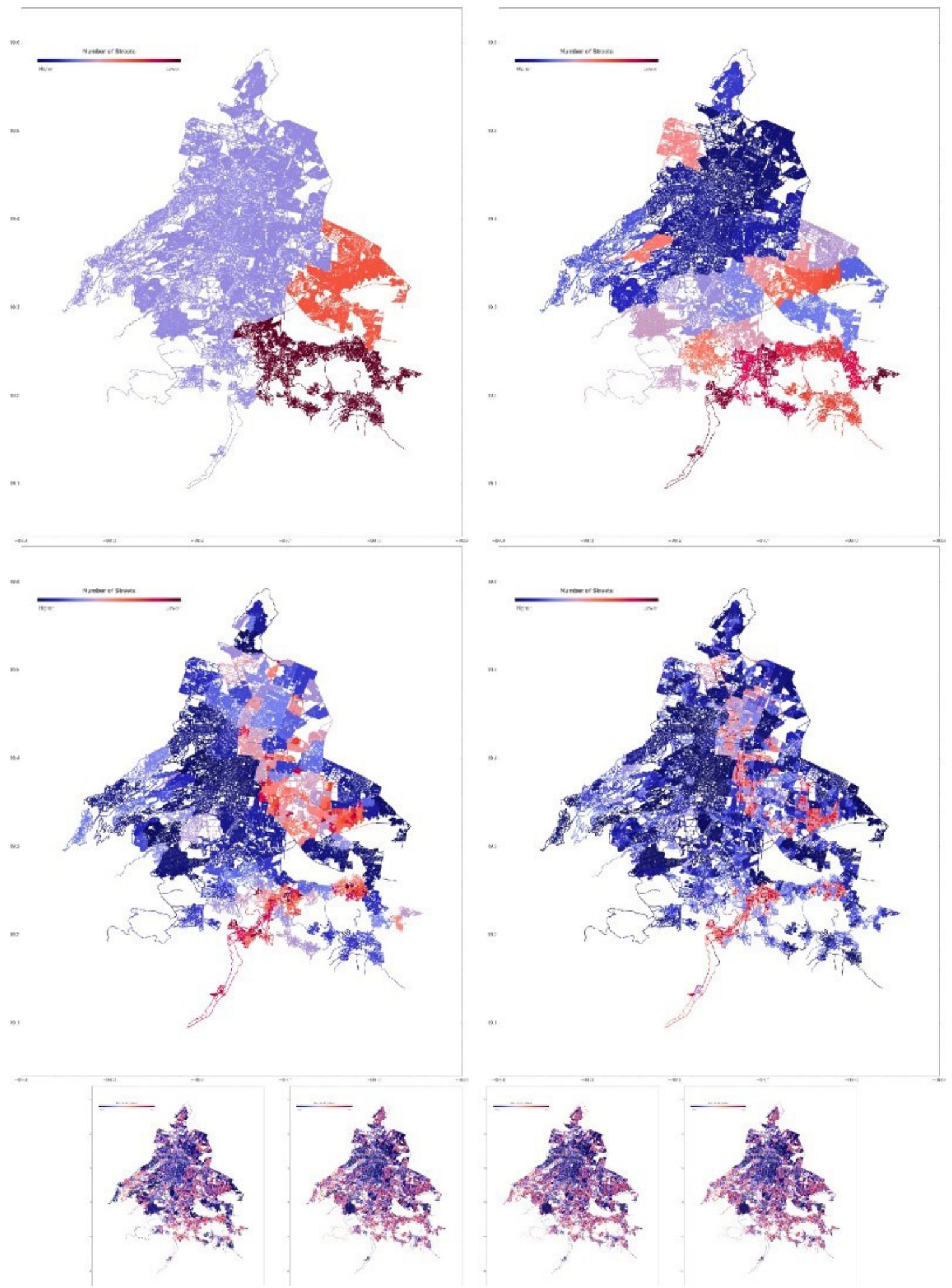

A: First Level, B: second level, C: third level, D: fourth level, E: fifth level, F: sixth level, G: seventh level, H: eighth level. 
As the result of the area comparison, we present the following stacked bar graphs that depict the percentage of area covered by the geographical entity, the street community and the intersection of both and for the case of delegations the figure also includes a map presenting how the street communities look like when matched their respective delegation. For the comparison of neighborhoods, the map is no longer useful, and we just present the distribution of area coverage. Using the second, third and four level for Mexico City, and just the second and third level for Monterrey. Communities for higher levels are too small to match any administrative division, therefore, those calculations were omitted. And lastly, plots of the number of streets gather by communities against their median betweenness centrality for different levels:

Figure 7. Monterrey comparisons of area covered by streets communities against delegations and neighborhood areas

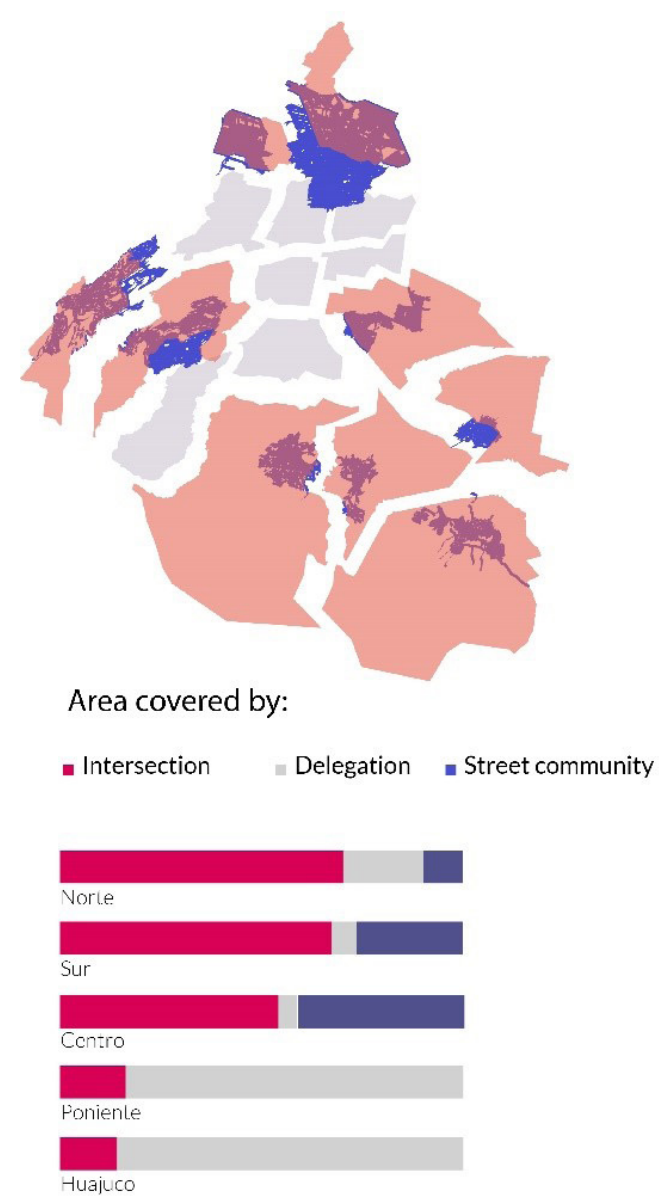
Area covered by:

- Intersection $\quad$ Delegation $\quad$ Street community
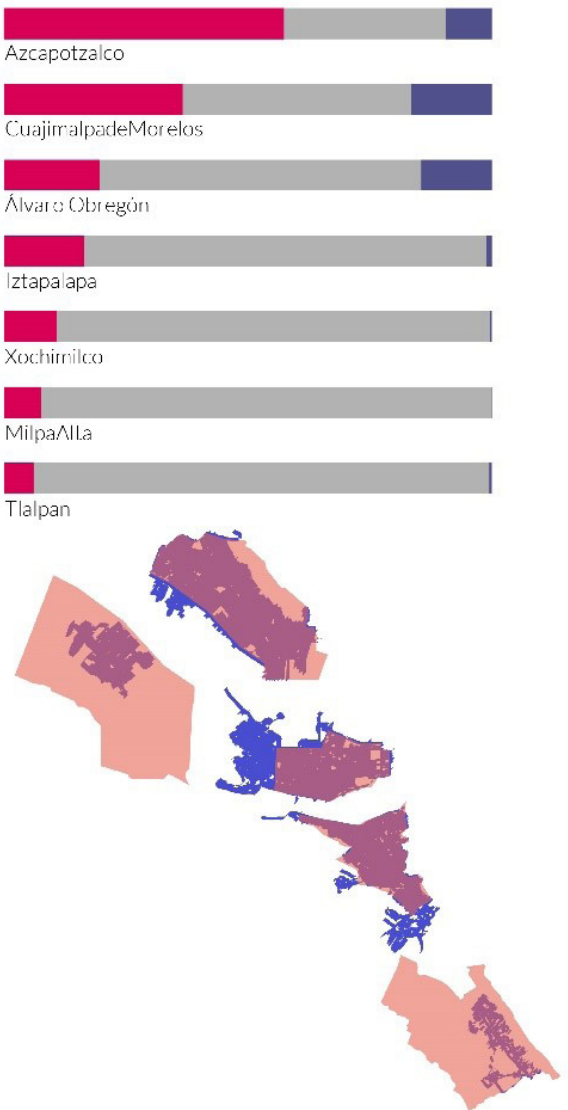

A: Municipal delegations of Monterrey City (territorial districts) overlap with the area covered by streets of the same community and its respective bars representing those areas. B: Neighborhoods of Monterrey City overlap with the area covered by streets of the same community and its respective bars representing those areas. 
Figure 8. Mexico City comparisons of area covered by streets communities against delegations and neighborhood areas

\section{Area covered by:}

- Intersection

- Street community

Neirborhoods

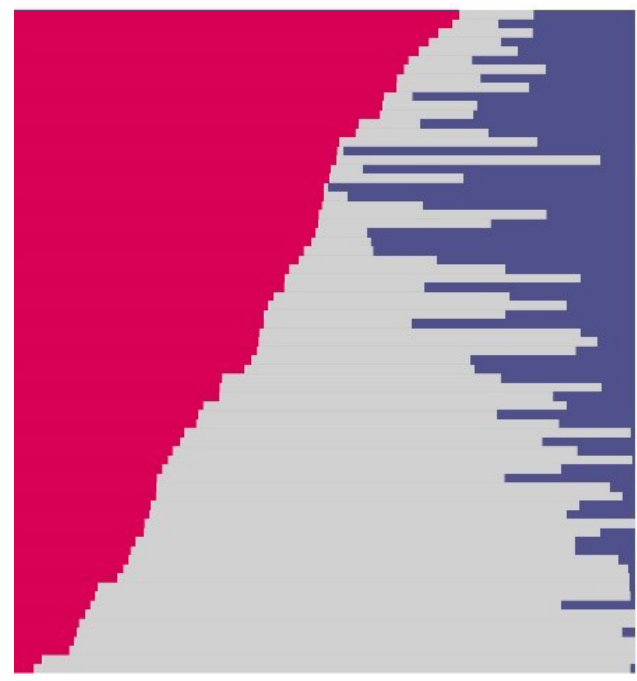

A. Mnnterrev neirhorhonds

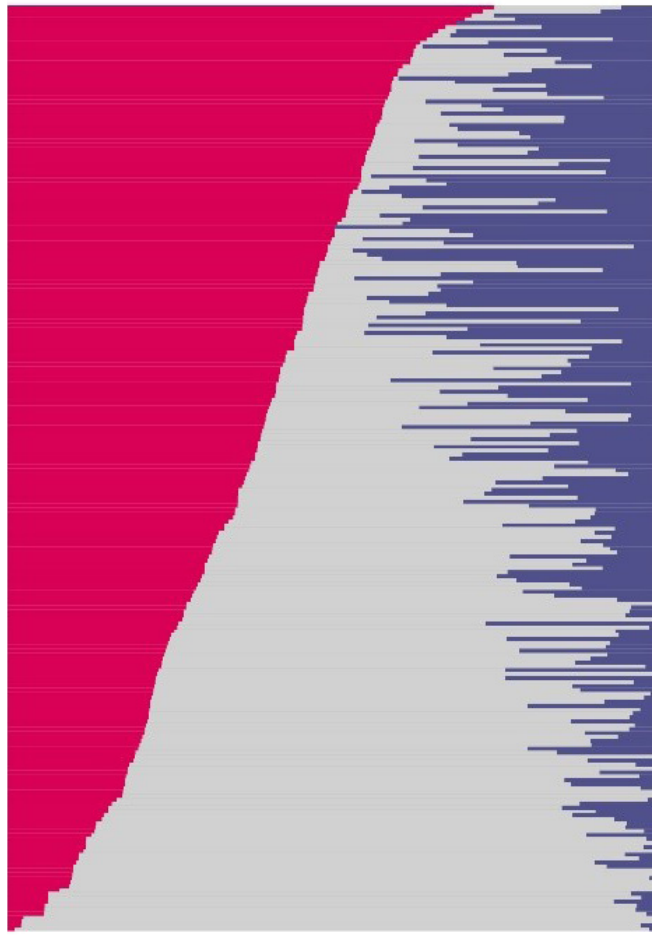

B: Mexico city neirborhoods

A: Area of street community against Delegations of Mexico City overlap with the area covered by streets of the same community and its respective bars representing those areas B: Neighborhoods of Mexico City overlap with the area covered by streets of the same community and its respective bars representing those areas. 
Figure 9. Size of communities against the median betweenness centrality in the communities of Monterrey

A: First level, B: Second level, C: Third level.
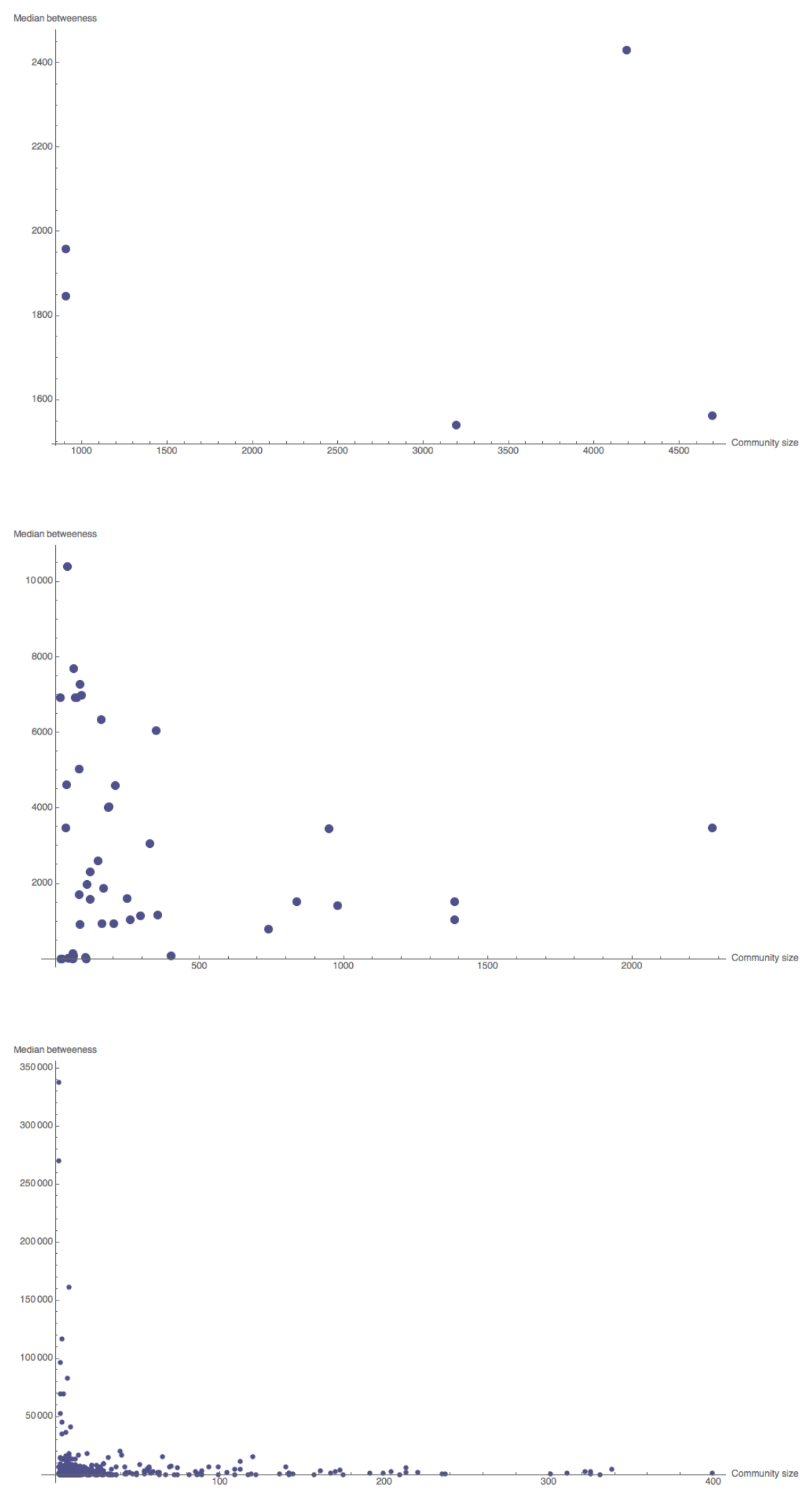
Figure 10. Size of communities against the median betweenness centrality in the communities of Mexico City

A: First level, B: Second level, C: Third level.
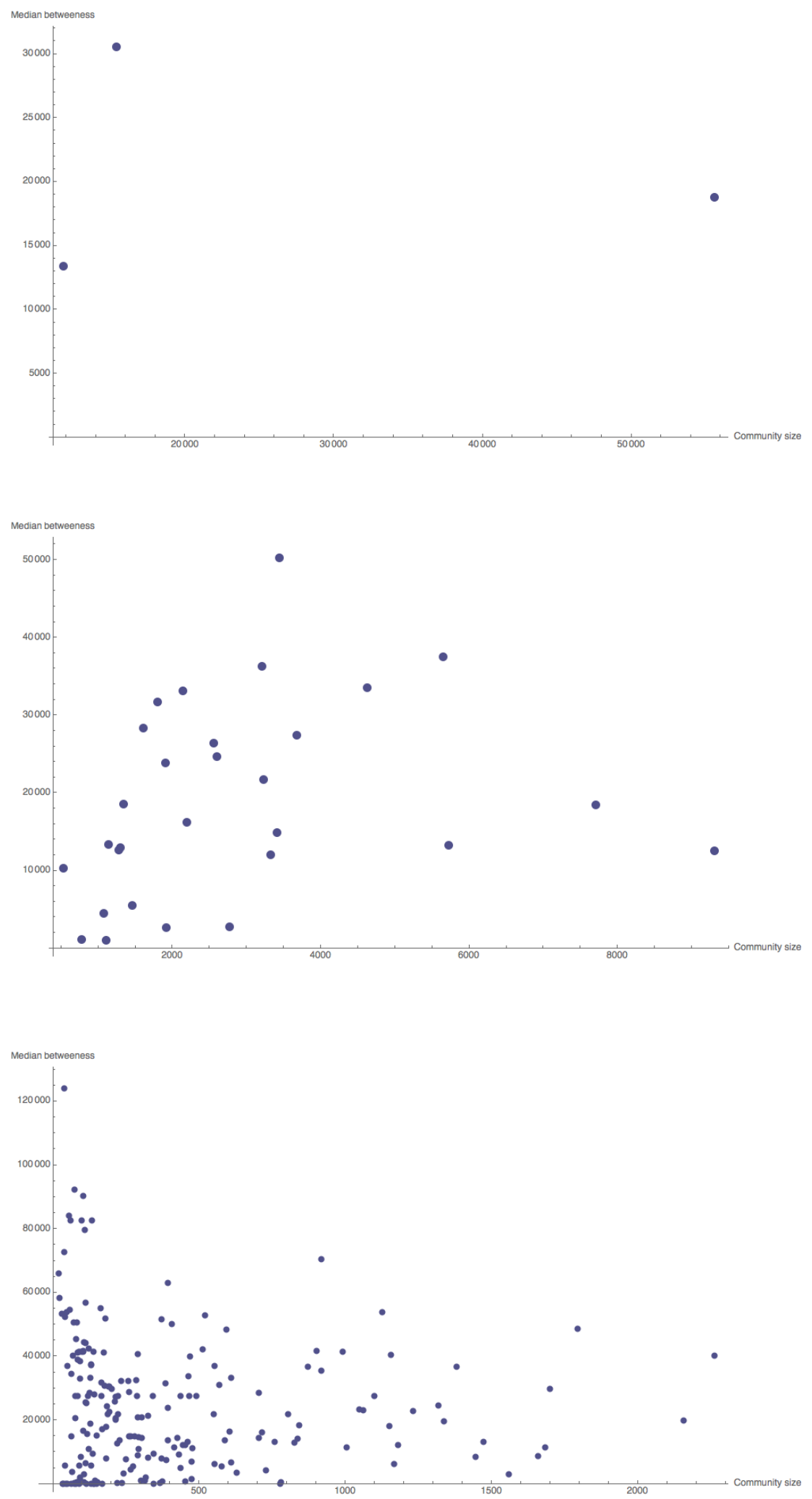


\section{DISCUSSION.}

The disparities of Monterrey and Mexico City are reflected in their respective road infrastructures: Monterrey road network consist of 13880 streets while Mexico City has 82737 streets. However, as depicted on figure 4 the community size distributions of their levels present similar shapes: the first level of both cities have large standard deviations and few elements that form a coarse-grained system; and as the level increases the distributions start to present skewness and outliers to the left (although the standard deviation diminishes), indicating that distributions for higher levels are less disperse, with few communities gathering more streets than most of the communities at that level.

The level of deepness in the partition allows to focus on the city road network at different scales; first partition levels give general information of accessibility and road infrastructure among the city, while communities at the last levels describe more specific aspects. The first level Monterrey presents an homogeneous division with five communities of similar areas, meanwhile Mexico city consist of one community covering the more than half of the city and two smaller regions; a division that reflects inequalities in the distribution of road infrastructure.

At the second level partition, all south region of Monterrey (Huajuco delegation) is divided into several communities, each gathering few streets. The zone partition is a consequence of the land use, most of the residential areas in that zone have small side streets and alleys. All those communities are connected by only one main road (Carretera Nacional) and parallel secondary roads that connect with each other ( $\mathrm{La} \mathrm{Luz}$ avenue that continues as Antiguo Camino to Villa de Santiago and later becomes Camino Real) which is part of the reason why the area appears fragmented into small zones.

The second level partition in Mexico City presents the southwest orange region (a collection of several neighborhoods inside Álvaro Obregón delegation) and the northwest pink region (Atzcapotzalco delegation), the first being a residential zone and the second, a delegation itself with its own dynamics. On the other side the south and southeast brown communities at the second level have the same problems as Monterrey, those communities correspond to small and distant towns at the borders of Mexico City that are in fragmented areas: San Miguel Topilejo and Parres el Guarda (towns of Tlalpan delegation next to the border with Morelos); San Andres Mixquic and San Nicol'as Tetelco (towns of Tlahuac at the border with Estado de México).

Further segmentation on each of the graphs also show important information, however it will not be discussed here due to the specificity required to describe each zone inside the map.

At different levels some communities are preserved almost the same, for instance, Monterrey's communities above and below Catarina River, kept their streets almost the same from the third through the sixth level which indicate a highly connected cluster of streets. Meanwhile, in Mexico City, delegation Benito Juarez is kept almost the same from the second to the fourth partition.

Frontiers of the city such as the Catarina River in Monterrey or the hill Cerro de la Estrella along with the ring road Periférico are visible at the first level partitions created by Infomap, which reflects that natural and human created frontiers in the city influence the road network layout. However, urban areas are the result of many different interactions, therefore it is not expected to find a perfect match between city zones and communities found with Infomap, for instance, when the area of communities is compared with administrative divisions, large geographical entities at the borders of the city are not fully covered by communities due to the heterogeneous street coverage; this is the case in border delegations like Huajuco in Monterrey, and Milpa Alta in Mexico city that have fewer street infrastructure compared with more centric areas. Particularly, when communities of Monterrey are compared with its delegations, the area overlapped has a median coverage percentage of $54 \%$, meanwhile for Mexico city the median of area intersected between communities and delegations is of $16.49 \%$, a very low percentage due to south delegations like Milpa Alta (overlapping 7.5\% of the delegation area), Xochimilco (with 10.8\% coverage) and Tlalpan (6\% area coverage) that have a small coverage of streets compared to the delegation because those limits of the city have fewer streets, for instance, almost all the infrastructure of Milpa Alta is in the community depicted in fig. 7.

For Monterrey, there were 73 communities of streets that match neighborhoods with a median of $39 \%$, from the third partition, some of those 
neighborhoods are Croc, Barrio San Luis, Barrio San Carlos and Barrio de la Industria; meanwhile the division of Mexico city road network matched 236 neighborhoods with a median of $37 \%$, the majority of those communities were from the third level partition, in which neighborhoods like Doctores, Obrera, Algar'in, Viaducto Piedad, Moderna, Prado Churubusco and Cualhuac'an were visible.

The Infomap algorithm detect communities based on the trajectories of a random walker, therefore, it was expected that smaller communities at the first partitions were a consequence of poorly connected areas that keep the random walker inside their area.

However, according to the graphs in figures 9 and 10 , the comparison of betweenness centrality (a measurement of connectedness that quantify the number of shortest paths that pass through a vertex) against community street size does not present a relationship, there are small communities with the highest and lowest values of betweenness. Examples of high connected small communities at the second level are the streets in La Rioja and Granja Postal neighborhoods, as well as the central community joining Asarco and Centrika neighborhoods for Monterrey, and for Mexico City, small street communities that cover Granjas San Antonio and Los Reyes Culhuac'an neighborhood, Area Federal San Nicolas Tolentino neighborhood, San Mateo Xalpa town and Santiago Tepalcatlapa town have also high values of betweenness. Meanwhile, among the small communities with low connectivity (as measured by the betweenness centrality) are Paseos Churubusco in Mexico City and Cumbres Elite, 2do, 5to, 7o y 80 Sector for Monterrey.

There could be several reasons for this inconsistency, one is the fact that the streets are not perfectly mapped, and there are single streets represented by several dis-joined segments, each segment is analyzed separately as a different street in Infomap; creating a misinterpretation of the real dynamics of the city. Also, if the distribution of betweenness centrality values in smaller communities have a low standard deviation and is probable for the median to have similar high centrality values. The last one is due to the fact that frontiers inside the city shape the road infrastructure, therefore, those communities could be the result of interactions between physical and human elements of the city.
As mentioned on the methodology, for this analysis it is always assumed that junctions and streets work on both ways (due to the street data used). Two important improvements of the method -supported by the Infomap algorithmwould be to weight the nodes of the graph with the actual fluxes of people and to restrict the movement inside the graph by using arrows edges directions creating an oriented and weighted graph to represent the road network.

\section{CONCLUSION.}

The method divides the streets of a city into communities based on the connectivity of their road network graph, where paths inside the graph represent real routes in the city and consequently the flow base partition generated by Infomap is created by real street dynamics.

The partitions preserve some physical and administrative frontiers inside the city, however they communities don't match perfectly with zones of the city such as neighborhoods of delegations. This is a useful method to analyze the street infrastructure at different scales and to compare whether the street intersections are useful to transit around the city effectively. C

\section{SUPPORTING INFORMATION.}

\section{Appendix.}

The community detection algorithm Infomap is an open source code that optimizes a flow based method called the map equation. Its operation is based on the duality between compressing data and detecting significant patterns or structures of the data. The algorithm infers the adequacy of a graph partition based on improvements compressing its information (Rosvall, Axelsson \& Bergstrom, 2009). It starts by assigning a module to every vertex and joining neighborhood vertex into the same module depending on how well the data can be compressed. The algorithm continues by moving random vertex (and even modules) into other modules until no move generates an improvement in data compression. To create a hierarchy in the structure, the procedure is repeated with a new graph constructed from the previous modules as vertexes and keeping the edges between those modules. Finally, given the fact that the algorithm is stochastic, partitions 
may deviate from one and other every time Infomap is executed. To overcome those issues the algorithm is repeated several times: only the partition with the best data compression is stowed (Edler \& Rosvall, 2018). Construction and evaluation of a graph partition is determined entirely by improvements in data compression, which translates into decreases in code length rated by the map equation. Its approach is that structures inside a complex system are determined through a flow modeled by several iterations of a random walker constrained in the graph.

Flow description can be compressed using different sets of modules as graph partitions. With the Huffman code, modules and nodes are assigned codewords determined by the random walker visit frequency. Then flow is described by a sequence of codewords indicating the order in which modules and nodes were visited. Each encoding have a lower bound on code length $L(M)$, determined by Shannon's entropy of the module codewords index $H(Q)$ weighted by the sum over the probabilities $q_{i}$ to exit module $i$ and the entropy of the vertex codewords $H\left(P^{i}\right)$, inside module $P^{i}$, weighted by the probability $p_{\alpha}$ to visit vertexes in module $i$ and to exit that module:

$L(M)=H(Q) \sum_{i=1}^{m} q_{i}+\sum_{i=1}^{m} H\left(P^{i}\right) \sum_{a \in i}\left(p_{a}\right)+q_{i}$

(Rosvall, Axelsson \& Bergstrom, 2009)

\section{ACKNOWLEDGMENTS.}

The authors thank the financial support given by the National Council of Science and Technology (CONACYT) for the project CB-2016-297673: Correlation between the topological concectivity of the urban network and the areas that are identified as a community in the urban imaginary.

\section{REFERENCES.}

Bettencourt, Lobo, \& Strumsky, 2004. Bettencourt, L., Lobo, J. and Strumsky, D. (2004). "Invention in the City: Increasing returns to scale in metropolitan Patenting”. Retrieved December, 2018, from https://pdfs.semanticscholar.org/

Bettencourt et al, 2007. Bettencourt, L., Lobo, J., Helbings, D., Kuhnert, C. and West G.
( 2007). Growth, innovation, scaling, and the pace of life in cities. PNAS 104 (17). doi: 10.1073 pnas.0610 172104

Cardillo et al, 2006. Cardillo, A., Scellato, S., Latora, V., Porta, S. (2006).Structural properties of planar graphs of urban street patterns. Physical Review E, 73(6). doi:10.1103/physreve.73.066107

Chartrand \& Zhang, 2012. Chartrand, G. and Zhang, P. (2012). A First Course in Graph Theory. Mineola, NY: Dover.

Edler D., Rosvall M. ( 2018) "Source code for multilevel communitydetection with Infomap". Map Equation. Retrieved in September 2018 from http://www.mapequation.org/code.html

Ferrara et al, 2014. Ferrara, E., De Meo, P., Catanese, S. and Fiumara, G. (2014). Detecting criminal organizations in mobile phone networks. Expert Systems with Applications 41

Fortunato, 2010. Fortunato, S. (2010). Community detection in graphs. Physics reports 486, $75-154$

González-Estrada, 2014. González -Estrada, A. (2014). Non parametric estimation of gross domestic product in the municipalities of Mexico. Revista Mexicana de Ciencias Agrícolas 5 (8), 1391-1404.

González-Estrada \& Gallegos-Cedillo, 2014. González -Estrada, A., and GallegosCedillo, G. (2014). The gross domestic product of municipalities of Mexico: II. Estates M-Z. Revista Mexicana de Ciencias Agr'icolas 5 (8), 1405-1421.

Hillier, 1996. Hillier, B. (1996). Cities as movement economies In Space is the machine London, United Kingdom. University of Cambdridge.

Hillier \& Iida, 2005. Hillier, B., Iida, S. (2005). Network and Psychological Effects in Urban Movement. Lecture Notes in Computer Science, 475-490. doi:10.1007/11556114 30

Hillier, 2009. Hillier, B. (2009). The genetic code for cities - is it simpler than we think?, keynote paper for the conference Complexity theories of cities have come of age, Netherlands, September 2009.

INEGI, 2010. Instituto Nacional de Estadística y Geografía. (2010). Censo de población y vivienda (2010). Perfil sociodemográfico: Estados Unidos Mexicanos. México

Jiang, 2003. Jiang, B.(2003). Topological analysis of urban street networks. Environment and 
Planning B: Planning and Design 31.

Lancichinetti \& Fortunato, 2009. Lancichinetti, A., Fortunato, S. (2009). Community detection algorithms: A comparative analysis. Physical Review E, 80(5). doi:10.1103/physreve.80.056117

Luo, 2016. Luo, S., Morone, F., Sarraute, C., Travizano, M. and Makse, H. (2016). Inferring personal economic status from social network location. Nature Communications.

Marshall, 2016. Marshall, S. (2016) Line structure representation for road network analysis. The Journal of Transport and Land Use 9 (1), 29-64.

Nystuen \& Dacey, 1961. Nystuen, J. and Dacey, M. (1961). A graph theory interpretation of nodal regions. Papers and Proceedings of the Regional Science Association 7

Ratti et al, 2010. Ratti, C., Sobolevsky, S., Calabrese, F., Andris, C., Reades, J., Martino, M., Claxton, R. and Strogatz, S. H. (2010). Redrawing the Map of Great Britain from a Network of Human Interactions. PLoS ONE, 5(12), e14248. doi:10.1371/journal.pone.0014248

Reijneveld et al, 2007. Reijneveld, J., Ponten, S., Berendse, H. and Stam, C. (2007). "The application of graph theoretical analysis to complex networks in the brain". Clinical Neurophysiology. pp118. (Capitulo de Libro)

Rinzivillo et al, 2012. Rinzivillo, S., Mainardi, S., Pezzoni, F., Coscia, M., Pedresch D. and Giannotti, F. (2012) Discovering the Geographical Borders of Human Movility. Künstl Intell (2012) 26:253-260. doi:10.1007/s13218-012-0181-8

Ritchie \& Roser, 2018. Ritchie, H. and Roser, M. (2018). "Urbanization”. Published online at OurWorldInData.org. Retrieved in January 2019 from: https://ourworldindata. org/urbanization

Rosvall \& Bergstrom, 2011. Rosvall, M. and Bergstrom, C. (2011). Multilevel compression of random walks on networks revel hierarchical organization in large integrated systems. PLoS ONE 6

Rosvall, Axelsson \& Bergstrom, 2009. Rosvall, M., Axelsson, D. and Bergstrom, C. (2009). The map equation. The European Physical Journal Special Topics 178 13-23.

Roth et al, 2011. Roth, C., Kang, S. M., Batty,
M., Barthélemy, M. (2011). Of Urban Movements: Polycentric Activity and Entangled Hierarchical Flows. PLoS ONE, 6(1), e15923. doi:10.1371/journal. pone. 0015923

Schläpfer et al, 2014. Schläpfer, M., Bettencourt, L., Grauwin, S., Rashke, M., Claxton, R., Smoreda, Z., West, G. and Ratti, C. (2014). The scaling of human interactions with city size. J. R. Soc. Interface 11 13-23.

SEDESOL \& CONAPO, 2012. Secretaría de Desarrollo Social and Consejo Nacional de Población. (2012). Sistema Urbano Nacional 2012 [National Urban System 2012]. México.

Sosa, 2017. Sosa, L. (2017). Diseño basado en sistemas complejos [Design based on complex systems]. Monterrey, México: Labyrinthos editores.

White, Engelen \& Uljee, 2015. White, R., Engelen, G. and Uljee, I. (2015). Modeling cities and regions as complex systems from theory to planning applications.

Zhong et al, 2014. Zhong, C., Müller, S.,Huang, X., Batty, M. and Schmitt, G. (2014) "Detecting the dynamics of urban structure through spatial network analysis". International JournalofGeographicalInformationScience. doi:10.1080/13658816.2014.914521 